Article

\title{
Grey Regulatory Focus Theory Weighting Method for the Multi-Criteria Decision-Making Problem in Evaluating University Reputation
}

\author{
Moses Olabhele Esangbedo *(D) and Sijun Bai \\ School of Management, Northwestern Polytechnical University, Xi'an 710072, China; baisj@nwpu.edu.cn \\ * Correspondence: moses@nwpu.edu.cn; Tel.: +86-151-09289227
}

Received: 26 December 2018; Accepted: 8 February 2019; Published: 14 February 2019

\begin{abstract}
Evaluating the reputation of higher institutions is important as a benchmark for the continuous development of universities. In multi-criteria decision-making (MCDM), the estimation of the criteria weight is significant in improving the accuracy of the evaluation results. However, criteria weights assigned by decision makers (DMs) can be inaccurate when not measured from the orientations from which the DMs pursue their decision goals. This paper combines the grey system theory (GST) and regulatory focus theory (RFT) in estimating the weights of criteria by measuring the promotional and prevention focus orientations of the DMs and representing it as grey numbers. In this paper, we showed not all weight measurements from the DMs are symmetrical. In essence, to improve the accuracy of the MCDM weights, the grey regulatory focus theory (GRFT) weighting method is proposed to estimate the weights of an MCDM problem as well as aggregating the weights of the group DMs, thereby overcoming the limitation of a single orientation measurement. Furthermore, the GRFT weighting method is applied in ranking four universities in Xi'an city of China from a sample data from 1200 students. The most reputable university is consistent with the other ranking indexes in the literature.
\end{abstract}

Keywords: university reputation; regulatory focus theory; grey system theory; group decisionmaking; multi-criteria decision-making (MCDM); weighting; uncertainty decision-making

\section{Introduction}

In an increasingly competitive environment, universities need to provide a consistent institutional image through good visibility, since universities are aware of the importance of generating an image that is strong in the vision of their target audiences [1]. Generally, the visibility of an institution is a vital issue for the display of its training offer, the validation of its scientific potential as well as the flamboyance of its buildings, equipment, and budgetary ease. Few higher education institutions succeed to valorize their wealth and diversity of its national and international relations. With over 2879 numbers of college and university in the People's Republic of China in 2017 [2], evaluating the reputation of all these institutions may be cumbersome, such as a comparison of the lower tier universities without the direct assistance from the Ministry of Education. In China, the higher education entrance examination (Gao Kao) can be a strong determinant for the future of most Chinese students, and these students, ideally, work towards the most reputable university their abilities can secure to have a sense of psychological satisfaction.

Psychology helps us to understand people's minds, their motivations, and the way they take decisions. Psychology can be defined as the science that studies human behaviour and mental processes through various research methods and empirical observation [3,4]. The cognitive processes and responses not only imply the actions of people, but also their feelings, memories, perceptions, thoughts, 
mental processes as well as body functions. Decisions are made either towards having pleasure or avoiding pain, in other words, increasing profit or reducing risk. This observation was crystallized by Higgins [5], who developed the regulatory focus theory (RFT). RFT explains people's motivation in achieving their goals from two different orientations, which is a promotion and preventive focus. Promotion focus oriented people are individuals who pay more attention to secure the enjoyed pleasures in accomplishing their decision goals rather than the pain that can be caused by their decisions. On the other hand, preventive focus orientated people are those who pay more attention to avoid the inflicted pain in pursuing their decision goals instead of the pleasure that is obtainable as the outcome of their decision. Now, these kinds of individuals make up the university management that drives the university culture through the cumulative decision they make based on their orientations. Also, regardless of the decision criteria, the outcome is tailored by the weights allocated by the decision makers' (DMs) RFT orientations.

Furthermore, decision-making is a term that describes the process of how people choose to solve problems that are presented, and the trigger of decision-making is the existence of a problem. The problem diagnoses, searches, and evaluates alternatives as well as the final choice of a decision, constituting the basic stages of solving a decision-making problem. The main components for solving multi-criteria decision-making $(\mathrm{MCDM})$ problems are distinct alternatives with their performances based on their evaluation criteria and the weights of these criteria [6]. When considering some real-life problems, there are uncertainties that should be put into consideration in the decision process. In this regards, the grey system theory (GST) is used to deal with uncertainty in this research by using interval grey numbers to represent the aggregated weights of the DMs and the performances of the alternatives that are ranked $[7,8]$.

Specifically, university rankings have increased in the last decade due to the globalization of competition among higher education within the context of the international knowledge society. Also, part of the interest in university rankings is the ever-increasing demand for comparable information from students, their families, and the growing need on the part of governments and society for a greater responsibility of universities towards their communities, which translates into greater demands for quality in the services provided to the nation. Although the ministry of education in most countries has their different methods in evaluating and ranking universities in their respective countries, there are some university ranking systems commonly known to academia. Among these rankings are the Academic Ranking of World Universities (ARWU) [9], CWTS Leiden (Centre for Science and Technology Studies (Centrum voor Wetenschap en Technologische Studies) [10], Performance Ranking of Scientific Papers for World Universities (PRSPWUN) [11], Quacquarelli Symonds (QS) [12], Times Higher Education (THE) [13], U-multi rank, and the University Rankings based on Academic Performance (URAP) [14]. While some ranking systems may use equal-weight for the evaluation, a good number of them use whole number weights in tens that do not consider the uncertainties of the DMs' perspective, and there is room for improvement. For example, the ARWU assign the weights of $10 \%$ to the quality of education; $10 \%$ to per-capita performance, $20 \%$ to staff of an institution winning Nobel prizes and field medals; $20 \%$ to highly cited researchers in 21 broad subject categories; $20 \%$ to papers published in Nature and Science; and $10 \%$ to papers indexed in the Science Citation Index-expanded and Social Science Citation Index [15]. Similarly, the QS allocates a criteria weight of $5 \%$ to the international student ratio; $5 \%$ to the international staff ratio; $10 \%$ to employers' reputation; $20 \%$ to citations per faculty; $20 \%$ to the faculty per student ratio; and $40 \%$ to an academic paper review [16]. Another example is Times Higher Education (THE) criteria that assigns $2.5 \%$ to industrial income; $7.5 \%$ to international outlook; $30 \%$ to citations; $30 \%$ to research; and 30\% to teaching [17]. It is evident that weights are significant to rank universities and the accuracy of these weights are important [18].

Thus, it has become trendy to develop rankings (or ordered classifications) by evaluating and comparing the quality of institutions or systems. This research is motivated by the quest for the improvement of the accuracy of the weights for solving MCDM problems. The major contribution 
in this paper is the measurement of DMs' weights from two orientations based on the RFT and the transformation of it to grey weights for uncertainty decision-making. This paper is presented as follows: Section 2 gives the literature review, and Section 3 provides our research methods, which involves weighting the evaluation criteria using GST and RFT based on grey numbers for the estimation of the criteria weights. Next, Section 4 shows the application of the grey regulatory focus theory (GRFT) weighting method with the grey relational analysis (GRA). Lastly, Section 5 concludes this paper.

\section{Literature Review}

\subsection{Hybrid MCDM Methods}

In the literature, there are numerous combinations of the weighting and evaluation methods that form various hybrid methods to deal with uncertainty and vagueness in decision-making [19]. The fuzzy set, rough set, grey set as well as probabilistic models, such as evidential reasoning, are used as the main approaches to account for uncertainties. Some of these hybrid methods combine the pairwise comparison methods and the classical weighted sum model (WSM) [20].

Structuring a decision problem is an effective approach for tackling it. Dincer et al. [21] analysed the performance results of the European policies in energy investment using the quality function deployment (QFD) [22] and the balanced scorecard. Then, they assessed the customer and technical requirement using a hesitant fuzzy decision set combined with the decision-making trial and evaluation laboratory (DEMATEL) and the analytical hierarchical process (AHP) [23]. Also, the hesitant fuzzy technique for order of preference by similarity to ideal solution (TOPSIS) [24] was incorporated in weighting the technical requirements of a new service/product development process. In the selection of air traffic protection aircraft, Petrović and Kankaraš [25] applied DEMATEL to determine the evaluation criteria and AHP for weighting. Hu et al. [26] applied the DEMATEL with the analytical network process (ANP) [23] for weighting and ranking experts in evaluating the prediction power of experts using the GRA [7]. Roy et al. [27] developed a rough strength relational DEMATEL model to analyze the individual priorities for the key success factors of hospital service quality.

Pairwise comparison gives all criteria an equal opportunity for assessment, and there is some integration of the MCDM methods with the geographic information system (GIS). Shariat et al. [28] applied the fuzzy extension of the AHP, WSM, and TOPSIS in analyzing the risk in an urban stormwater infrastructure system. The GIS was integrated to solve the spatial MCDM problem. Ali et al. [29] applied the AHP to assess the suitability of a wind and solar farm based on GIS in Thailand. The AHP weight was directly used with the WSM. Arabameri [30] combined the AHP and TOPSIS method as a hybrid MCDM method. This was further compared with bivariate and multivariate statistical analysis as well as data mining approaches in assessing water mapping based on the GIS. Sahu et al. [31] developed the Taguchi SAW method to rank the cutting speed, feed, and depth of cut in a lathe machine. Then, the Taguchi TOPSIS method was employed to validate the rankings in their research.

Another application area of the hybrid MCDM methods is in efficient sustainable development. Zhang et al. [32] selected the best renewable energy project by employing a linear programming model to determine the weights as an extended interacting and MCDM method. Aghdaie et al. [33] applied the step-wise weight analysis ratio assessment (SWARA) [34] and the complex proportional assessment (COPRAS) [35] with GRA in market segmentation, where GRA integrated incomplete information in the model. Much later, this research was extended as fuzzy group decision-making [36]. Wang et al. [37] matched demand in reverse logistics in manufacturing as an MCDM problem. They applied a hybrid of the AHP and entropy weights combined with the grey multi attributive border approximation area comparison (MABAC) method [38] to evaluate the collection mode. Kamari [39] developed a soft systems methodologies (SSM) for assessing the barrier to sustainable renovation and employed the AHP and TOPSIS as a mixed method based on the SSM. Nie et al. [40] presented the Pythagorean fuzzy partitioned normalized weighted Bonferroni mean (PFPNWBM) operator, which considers a Shapley fuzzy measure. They illustrated the use of this operator in the selection of green raw material. 
The problem of an exponential increase of comparison in the AHP and ANP is addressed using the best and worst MCDM (BWM) methods [41]. Badi and Ballem [42] combined a rough set with BWM for weighting in the multi-attribute ideal-real comparative analysis of evaluating medical and pharmaceutical equipment. Similarly, to mitigate this problem, Pamučar et al. [43] developed a full consistency method (FUCOM) for approximating the weight of criteria in the MCDM model. The FUCOM is a subjective weighting method that determines the deviation from full consistency in the comparison. The FUCOM algorithm pairwise compares the criteria and only needs $n-1$ comparisons, which is less than the number of comparisons needed by the AHP [23] and BWM method. Also, Pamucar et al. [44] extended the FUCOM method to multi attributive ideal-real comparative analysis and was applied in evaluating cross-leveling in railway infrastructure. Then, Nunić [45] applied the FUCOM method in estimating the weights of criteria with MABAC for the evaluation of PVC carpentry manufacturers.

The uncertainty in fuzzy membership functions have led to other hybrid methods. Similarly, Aghdaie and Tafreshi [46] integrated the fuzzy set theory with the SWARA in the weight of the key performance index in the recency-frequency-monetary model. Also, Stanujkić and Karabašević [47] extended the WASPAS method [48] with an intuitionistic fuzzy number in evaluating a website and showed that it is an improvement over the other extension with a hamming distance. Singh and Garg [49] developed the symmetric triangular interval type-2 intuitionistic fuzzy set operations and the use of the Hamy mean to aggregate the operators. The company selection problem and the risk for an event was used to illustrate the use of the operator. Dursun and Arslan [50] combined the quality function development (QFD), linguistic hierarchies, and 2-tuple fuzzy linguistic, and COPRAS value for selecting the most appropriate material in the manufacturing of detergents. The development criteria for a new product was obtained using the QFD and the criteria weight from experts, then an assessment of the alternatives was conducted using the COPRAS method. Ye et al. [51] proposed the grey correlation accurate weighted determining method that combined interval-valued intuitionistic and fuzzy decision-theoretic rough sets in deciding the region for e-commerce development in Sichuan province of China. Some researchers use the fuzzy set as the main domain for dealing with uncertainty. Nonetheless, GST can also be applied in dealing with uncertainty.

\subsection{Grey System Theory}

The grey system theory (GST) was developed by Deng [52] to handle uncertainty. A simple interpretation of a grey system is an incomplete information system. In real life, every system can be categorized as an incomplete information system. In other words, if the information of the system is complete, then there is little or no room for further research. The emphasis in the GST is to what extent is the information incomplete, i.e., what is the shade of the grey system? Now, a white system is one with complete information, and a black system is a system with unknown information. A system with partial information is the grey system. In a timescale, the past is a white system, and the future is a black system, but a grey system is the present, in which we are in between the past and the future, the known and the unknown.

In GST, the grey number is used to represent incomplete systems. There are different types of grey numbers, the unbounded, bounded, and interval grey numbers. In this research, the interval grey numbers will be used. While an interval number is all the possible numbers within the lower and upper interval, an interval grey number is a single number within the lower and upper bound of the grey number. The GST is different from the classical statistical and probability methods that require a large data sample and should conform to a typical distribution [53]. On the other hand, GST stands to maximize the information presented for computation, and provide an interpretation of the data, regardless of how little the information is presented for analysis [8].

Although the GRA has been applied to solve lots of MCDM problems, GRA is used in logistics and industrial applications. Liu and Tong [54] applied GRA in selecting the optimal design strategy in an engineering automatic form by providing the correlation between the design and analytical 
factor. Yazdani et al. [55] combined QFD and GRA to evaluate performance in logistics management in a supply chain. The main criteria evaluated are the environmental indicators, economic downturn, and the social and cultural complaints. Although the fuzzy linguistic value was used to estimate the weights of the criteria, GRA was used in ranking the criteria for the evaluation of the supply chain. Sefidian and Daneshpour [56] developed the missing values imputation method that replaces the Euclidean distance with the GRA in the fuzzy clustering algorithm. Ramesh et al. [57] applied GRA in combination with the Taguchi based orthogonal array in ranking the control factors with regards to the output of the design of experiments (DoE) approach, thereby obtaining the setting for a better cutting force. Lai et al. [58] applied GRA in determining the most influential factor, imbibition recovery, on the spontaneous imbibition of a tight gas reservoir in the Ordos basin, Chain.

GST has been used in solving group decision-making problem. Commonly, the DMs' preferences are measured as linguistic values then aggregated or whitenized and used in conjunction with other MCDM evaluation methods. In aggregating the DMs' preferences, Mehrjerdi [59] and Wang et al. [60] used the grey arithmetic mean in aggregating the linguistic variables of the DMs for solving an MCDM system selection problem. However, Kang et al. [61] applied the geometric mean to aggregate the DMs' preferences in the selection of restaurants. Zhang [62] applied the correlative operator for combining the grey linguistic value of the DMs, and Ma et al. [63] equally applied the correlative operator for weighting in the evaluation of investment options. Jin et al. [64] proposed multiple harmony operators for aggregating group linguistic variables. Notwithstanding the operator used in aggregating the DMs' preferences, a lower-level problem of the DMs' preferences measurement approach remains, and there is a need to consider the orientations from which the DMs view the evaluation criteria, and to present an improved measurement instrument.

\subsection{Regulatory Focus Theory}

Regulatory focus theory, according to Crowe and Higgins [65], allows one to understand the fundamental ways we approach a task or a goal as it pertains to our motivation. Various factors can motivate people during target tracking, and we regulate our methods and processes while aiming and pursuing it. RFT suggests that motivational power is increased when the way in which people work towards a goal supports their regulatory focus. Individuals can pursue different goals with different regulatory orientations and explore opportunities. There are two different types of regulatory orientations that people use to achieve their goals: Promotion focus orientation and prevention focus orientation. According to Higgins [66], individuals use internal processes to achieve personal goals. Regulatory focus theory assists in predicting persuasion by manipulating communications that may depend on an individual's personal goals and characteristics [67].

Interestingly, Forster et al. [68] proposed the goal looms larger effect, which confirmed that people's motivation increases as they move closer to their goals based on their regulatory focus. In other words, motivation and performance on tasks towards a goal increase when the regulatory focus of the incentive and mean matches [69]. For example, Zhao and Pechmann [70] showed that effective communication is based on the synergy of the receiver's regulatory focus, the regulatory focus of the message, and the message frame. Besides investigating the motivation of people, Dijk and Kluger [71] hypothesized that the task type moderates task performance and their motivation. They confirmed that different tasks could be affected by one regulatory focus, as well as regulatory focus and task type explaining the variability of the feedback effect on task motivation and performance. On the other hand, Bullens et al. [72] showed the reversibility of a decision affects motivation, implying that a reversible decision strengthens prevention focus more than promotion focus. This implies that reversible DMs are more prevention focus than promotion focus ones, and this has some effect on the choice satisfaction of the DMs.

Some applications and investigations for RFT in decision-making have been presented, which support the upper echelons theory. Kuhn [73] presented how DMs make a judgment in hiring staff based on the promotion focus, i.e., selecting the good; and prevention focus, i.e., rejecting 
the bad. Ahmadi et al. [74] attempted to answer the question of whether managers are motivated to explore in the face of new technological change. The answers and explanation were dependent on the regulatory focus and fit of the DMs. Lai et al. [75] empirically investigated information system development team performance and confirmed that transformational leadership leads to promotional focus, while transactional leadership leads to prevention focus. Liao and Long [76] discovered that a company environmental innovation process is positively influenced by the top leader's promotion focus, but negatively influenced by their prevention focus. Song et al. [77] showed that institution-based trust impacts community commitment, which is moderated by RFT orientations.

Most importantly, Higgins and Cornwell [78] extensively discussed the frontier of RFT and presented the effects of both prevention and promotion focus on decision-making, but the aspect of the MCDM weighting method was not mentioned. Lastly, Lo Gerfo et al. [79] conducted neurophysiological testing of the RFT and showed DMs indeed could be either more promotion focused or more prevention focused. This research fills the gap in the literature that has not applied the RFT in MCDM in estimating the weights of the DMs in an uncertain decision-making environment by measuring the DMs' weight from both promotion and prevention focus orientations.

\section{Methodology}

\subsection{Measurement and Weighting Criteria}

The measurement criteria for the evaluation of university reputation consists of six first-level criteria, and 18 second-level criteria, as well as each second-level criterion having four variables. The set of four variables are reflective constructs for the estimation of the performances of the university base on each second-level criterion. In other words, every survey participant answered 72 questions as the variables. The main reasons these criteria were selected are because it can serve as a repetition of the quality of the past activities of the university [80-82]. Also, these deduced criteria capture the reflected image the university creates of the students. The details of the measurement criteria for obtaining the data from these university students are given by Chen and Esangbedo [83], and Table 1 summarizes the definitions of these criteria. In this paper, we focus on the weighting method based on the RFT.

Table 1. Summary of criteria for evaluating university reputation.

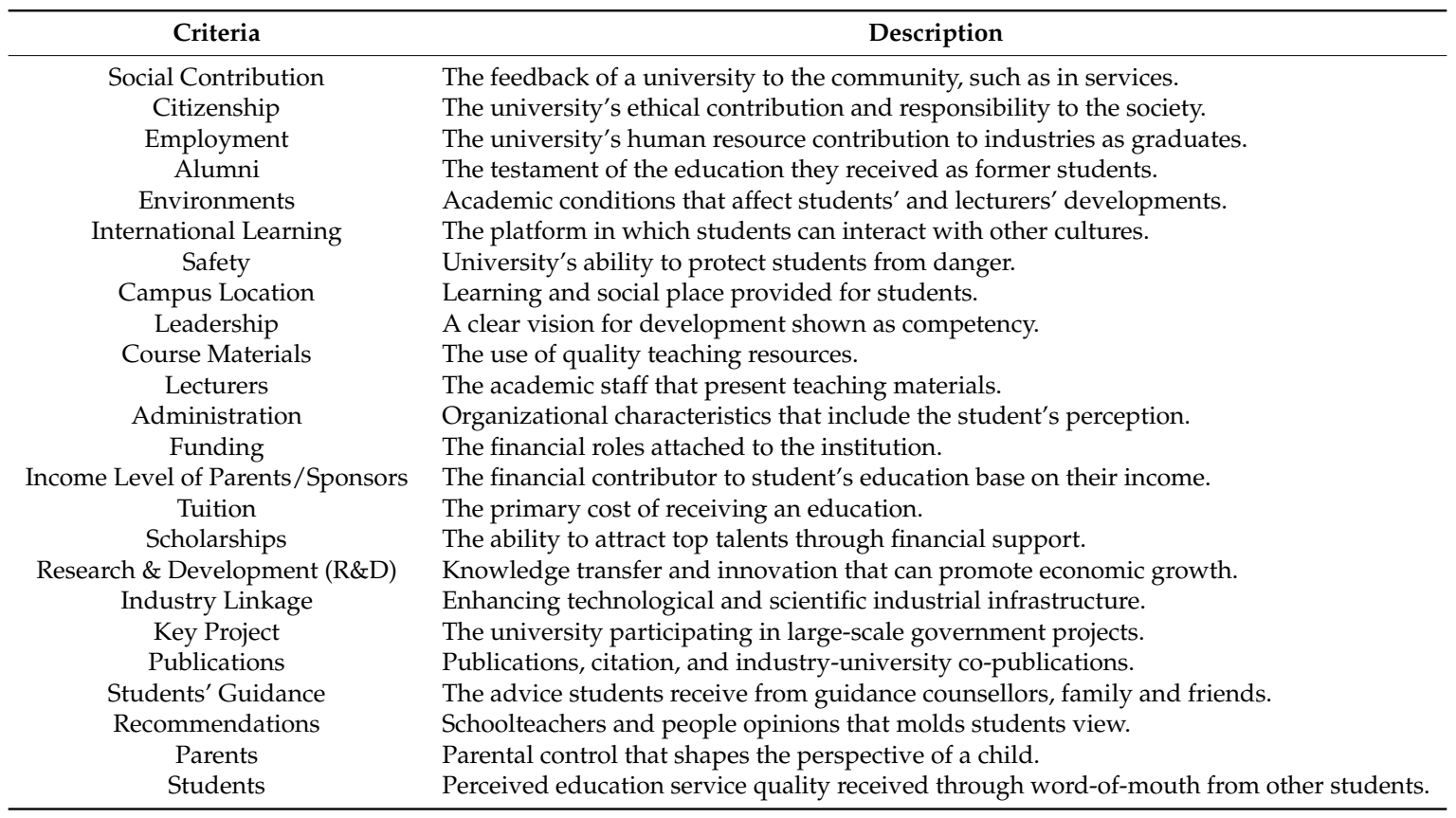


The model for the criteria weight measurement consists of a hierarchical structure with six first-level criteria and 18 second-level criteria. Each first-level criterion has three second-level criteria, and each of the second-level criterion is measured as both prevention and promotion focused measurements, and are represented as grey interval numbers as shown in Figure 1. In total, each DMs gave ratings to 42 weighting items, i.e., six items for the first-level criteria and 36 items for the second-level criteria (18 items each for both the prevention and promotion focused weightings) in the questionnaire.

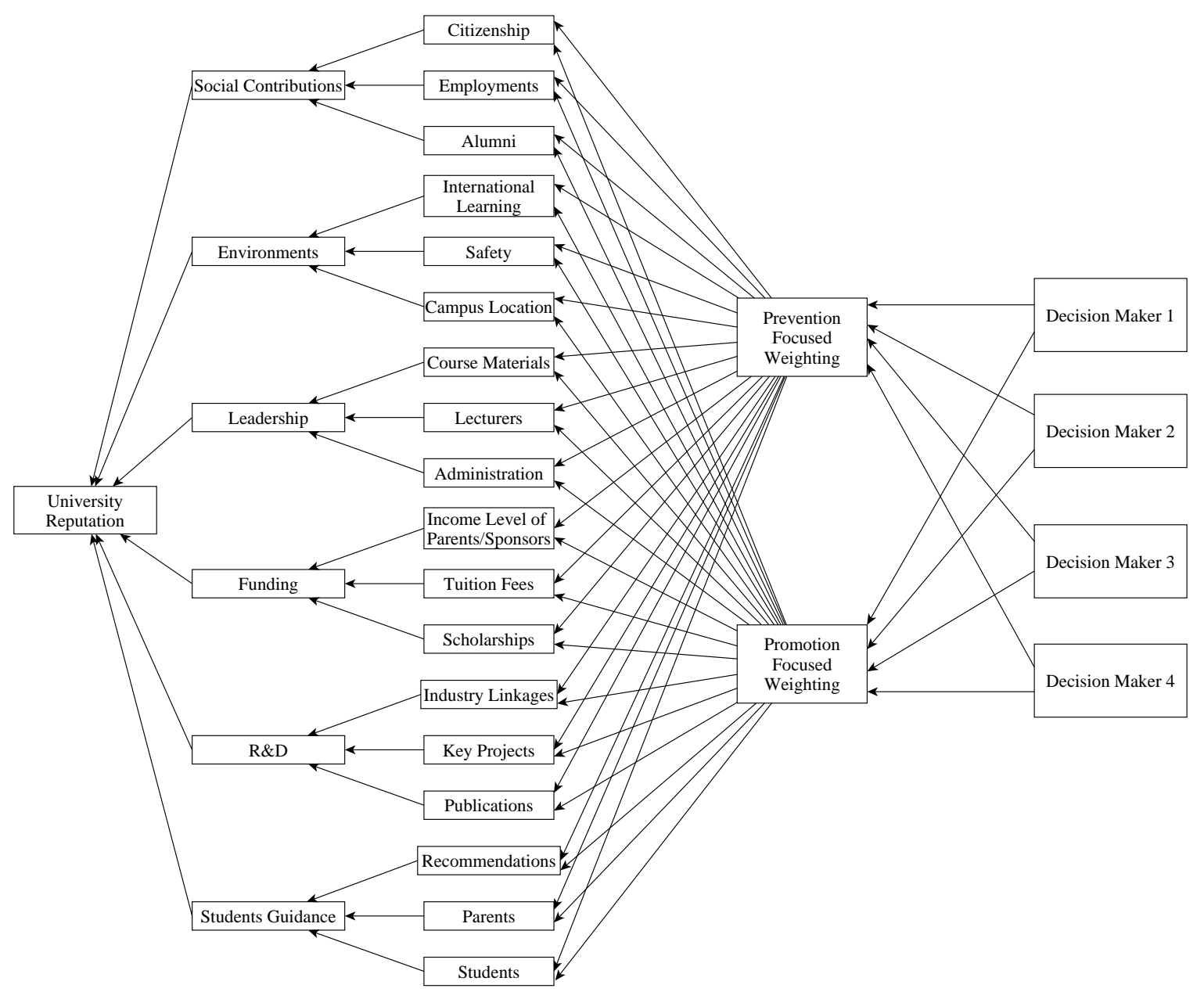

Figure 1. Grey Regulatory Focus Theory (GRFT) weighting model for the evaluation of university reputation: Adapted and modified [83].

\subsection{Grey Regulatory Focus Theory (GRFT) Weighting Method}

The main idea of the GRFT weighting method is to obtain the DMs' preferences from both the prevention and promotion focus and to represent it as interval grey numbers. Then, the weights are standardized so that the summation of the upper bounds of the grey weights are summed up to a unit value, which is used in the MCDM evaluation method. To begin, some basic operations of interval grey numbers. For an interval grey number of $\otimes a=[\underline{a}, \bar{a}]$ and $\otimes b=[\underline{b}, \bar{b}]$, where $\underline{a}<\bar{a}$ and $\underline{b}<\bar{b}$, as well as a crisp number of $c$, some basic operation these grey numbers is as follows $[84,85]$ :

Addition,

$$
\otimes a+\otimes b=[\underline{a}+\underline{b}, \bar{a}+\bar{b}]
$$

Multiplication,

$$
c \times \otimes a=[c \underline{a}, c \bar{a}]
$$




$$
\begin{gathered}
-c \times \otimes a=[-c \bar{a},-c \underline{a}] \\
\otimes a \times \otimes b=[\underline{a}, \bar{a}] \times[\underline{b}, \bar{b}]=[\min (\underline{a} \underline{b}, \underline{a} \bar{b}, \bar{a} \underline{b}, \bar{a} \bar{b}), \max (\underline{a b}, \underline{a} \underline{b}, \bar{a} \underline{b}, \bar{a} \bar{b})]
\end{gathered}
$$

Subtraction,

$$
\otimes a-\otimes b=\otimes a+(-1 \times \otimes b)=[\underline{a}-\bar{b}, \bar{a}-\underline{b}]
$$

Division,

$$
\otimes a \div \otimes b=[\underline{a}, \bar{a}] \times\left[\frac{1}{\underline{b}}, \frac{1}{\bar{b}}\right]
$$

The arbitrary distance between two interval numbers from $\otimes a=[\underline{a}, \bar{a}]$ to $\otimes b=[\underline{b}, \bar{b}]$ is [86]

$$
|\otimes a-\otimes b|=\max (|\underline{a}-\underline{b}|,|\bar{a}-\bar{b}|) .
$$

Now, the steps for the GRFT weighting method is as follow:

Step 1. Obtain the DMs ratings. The DMs ratings for each evaluation criterion can be obtained through a questionnaire that presents prevention and promotion focus questions. In this research, direct ratings by allocating percentage scores $(0 \%-100 \%)$ are used to measure the DMs preferences.

Step 2. Transform the DMs ratings into grey numbers. The grey interval numbers that satisfies all the DMs ratings are used to represent the first-level criteria. Then, the grey number ratings of the second-level criteria are measured as both the promotion and prevention focus orientations as the lower and upper bounds of the grey numbers. The transformation for the DMs ratings are:

1. For the first-level criteria, $C^{\prime}$. The DMs ratings for $C^{\prime}$ in grey numbers consist of the $\alpha$ th first-level criteria $c$ given as

$$
C^{\prime}=\otimes c_{1}, \otimes c_{2}, \ldots, \otimes c_{s},
$$

in which $s$ is the last first-level criterion and $\otimes \mathcal{C}_{\alpha}=\left[\underline{c}_{\alpha}, \bar{c}_{\alpha}\right]$, where the lower and upper bound are given as $\underline{c}_{\alpha}=\min _{1 \leq i \leq m}\left(D M_{i}\left(C_{\alpha}\right)\right)$ and $\bar{c}_{\alpha}=\max _{1 \leq i \leq m}\left(D M_{i}\left(C_{\alpha}\right)\right)$, respectively.

2. For the second-level criteria, $C^{\prime \prime}$ : The grey ratings is the minimum and maximum ratings by the DMs for each criterion.

$$
C^{\prime \prime}=\otimes c_{\alpha-1}, \otimes c_{\alpha-2}, \ldots, \otimes c_{\alpha-t}
$$

where $t$ is the last second-level criteria for each first-level criterion.

The aggregated grey ratings given by the group of $m$ DMs for the second-level criteria, $C_{\alpha-\beta}$, is

$$
\otimes c_{\alpha-\beta}=\left[\underline{c}_{\alpha-\beta}, \bar{c}_{\alpha-\beta}\right]=\left[\sum_{i=1}^{m} \underline{c}_{\alpha-\beta-i}, \sum_{i=1}^{m} \bar{c}_{\alpha-\beta-i}\right]
$$

where $\underline{c}_{\alpha-\beta-i}=\min \left(D M_{i, p}\left(C_{\alpha-\beta}\right), D M_{i, q}\left(C_{\alpha-\beta}\right)\right)$ and $\bar{c}_{\alpha-\beta-i}=\max \left(D M_{i, p}\left(C_{\alpha-\beta}\right), D M_{i, q}\left(C_{\alpha-\beta}\right)\right)$ are the lower and upper bound of the $D M_{i}$ grey ratings, which is a grey rating of $\otimes c_{\alpha-\beta-i}=$ $\left[\underline{c}_{\alpha-\beta-i}, \bar{c}_{\alpha-\beta-i}\right]$.

Step 3. Standardized the grey weights. The standardized weight is computed such that the sum of the criteria weights is equal to one unit, i.e., $100 \%$. Computing the standardized grey weight is done for the first-level and second-level criteria as given:

1. For the first-level criteria. The standardized weight for the first-level criteria, $W^{\prime}$ is the grey weight for the $\alpha$ th criteria is $\otimes w_{\alpha}=\left[\underline{w}_{\alpha}, \bar{w}_{\alpha}\right]$ where $\underline{w}_{\alpha}=\frac{\underline{c}_{\alpha}}{\sum_{\alpha=1}^{m} \bar{c}_{\alpha}}$ and $\bar{w}_{\alpha}=\frac{\bar{c}_{\alpha}}{\sum_{\alpha=1}^{m} \overline{\bar{c}}_{\alpha}}$. Thus,

$$
W^{\prime}=\otimes w_{1}, \otimes w_{2}, \ldots, \otimes w_{s}
$$


2. For the second-level criteria. The standardized weight for the second-level criteria, $W^{\prime \prime}$ is the grey weight for the $\beta^{\text {th }}$ criteria is $\otimes w_{\alpha-\beta}=\left[\underline{w}_{\alpha-\beta}, \bar{w}_{\alpha-\beta}\right]$ where $\underline{w}_{\alpha-\beta}=\frac{\underline{c}_{\alpha-\beta}}{\sum_{\beta=1}^{m} \bar{c}_{\alpha-\beta}}$ and $\bar{w}_{\alpha-\beta}=$ $\frac{\bar{c}_{\alpha-\beta}}{\sum_{\beta=1}^{m} \bar{c}_{\alpha-\beta}}$. Thus,

$$
W^{\prime \prime}=\otimes w_{\alpha-1}, \otimes w_{\alpha-2}, \ldots, \otimes w_{\alpha-t}
$$

where $k$ is the last term of the first level criteria.

Step 4. Compute the overall weights. The overall weights are the multiplication of the local weights of the first-level and second-level criteria.

$$
W=W^{\prime} \times W^{\prime \prime},
$$

Which have grey value for the second-level criteria as $\otimes w_{v}=\otimes w_{\alpha} \times \otimes w_{\alpha-\beta}$, where $v$ is the index of the criteria for the MCDM evaluation method, i.e., the second-level criteria index, $\otimes w_{v}=\left[\underline{w}_{v}, \bar{w}_{v}\right]$ and $\sum_{v=1}^{m} \bar{w}_{v}=1$

$$
W=\left(\begin{array}{llll}
\otimes w_{1} & \otimes w_{2} & \cdots & \otimes w_{n}
\end{array}\right)^{T}
$$

The weight transpose is a column matrix that can be used in other MCDM methods such as the WSM.

\subsection{Grey Relational Analysis with Grey Numbers}

GRA is a section of GST. The traditional GRA is computed with white numbers (crisp numbers) since it is a relational analysis of alternatives with a reference series. For the GRA to account for uncertainty, then the GRA with grey numbers is used. The approach of the GRA with grey numbers begins with constructing a decision matrix and normalizing it to compute the weighted decision matrix. Next, the reference alternative is obtained, and the grey relational grade is ranked. The steps for the GRA using grey numbers are as follows:

Step 1. Construct the hierarchical criteria model and obtain the raw data for the alternatives.

Step 2. Construct the grey decision matrix. The grey data from the decision table is extracted and placed in a grey decision matrix for computation using matrix operations.

$$
D=\left(\begin{array}{cccc}
\otimes d_{1,1} & \otimes d_{1,2} & \cdots & \otimes d_{1, n} \\
\otimes d_{2,1} & \otimes d_{2,2} & \cdots & \otimes d_{2, n} \\
\vdots & \vdots & \ddots & \vdots \\
\otimes d_{m, 1} & \otimes d_{m, 2} & \cdots & \otimes d_{m, n}
\end{array}\right) .
$$

where $\otimes d_{i j}=\left[\underline{d}_{i j}, \bar{d}_{i j}\right]$ is the grey number of the $j$ th criterion of the $i$ th alternative, for which $1 \leq i \leq m$ and $1 \leq j \leq n$, where $m$ and $n$ are the numbers of alternatives and criteria, respectively.

Step 3. Standardize the decision matrix. A standardized grey matrix $\otimes D^{\prime}$ is calculated, with the standardized element $\otimes d_{i j}^{\prime}=\left[\underline{d}_{i j}^{\prime}, \bar{d}_{i j}{ }_{i j}\right]$.

$$
D^{\prime}=\left(\begin{array}{cccc}
\otimes d_{1,1}^{\prime} & \otimes d_{1,2}^{\prime} & \cdots & \otimes d_{1, n}^{\prime} \\
\otimes d_{2,1}^{\prime} & \otimes d_{2,2}^{\prime} & \cdots & \otimes d_{2, n}^{\prime} \\
\vdots & \vdots & \ddots & \vdots \\
\otimes d_{m, 1}^{\prime} & \otimes d_{m, 2}^{\prime} & \cdots & \otimes d_{m, n}^{\prime}
\end{array}\right)
$$


In GRA, interval numbers are standardized through norm based on minimization of maximum distance [87].

$$
\left[\underline{d}_{i j}^{\prime},{\overline{d^{\prime}}}_{i j}\right]=\left[\frac{\underline{d}_{i j}}{\left\|d_{j}\right\|}, \frac{\bar{d}_{i j}}{\left\|d_{j}\right\|}\right]
$$

where

$$
\left\|d_{j}\right\|=\max _{1 \leq i \leq m} \bar{d}_{i j}
$$

Step 4. Compute the weighted standardized decision matrix. Given that the grey weight is $\otimes W=\left(\begin{array}{llll}\otimes w_{1} & \otimes w_{2} & \cdots & \otimes w_{m}\end{array}\right)^{T}$, then weighted standardized decision matrix is

$$
D^{*}=\left(\begin{array}{cccc}
\otimes d_{1,1}^{*} & \otimes d_{1,2}^{*} & \cdots & \otimes d_{1, n}^{*} \\
\otimes d_{2,1}^{*} & \otimes d_{2,2}^{*} & \cdots & \otimes d_{2, n}^{*} \\
\vdots & \vdots & \ddots & \vdots \\
\otimes d_{m, 1}^{*} & \otimes d_{m, 2}^{*} & \cdots & \otimes d_{m, n}^{*}
\end{array}\right)
$$

where

$$
\otimes d_{i j}^{*}=\otimes d_{i j}^{\prime} \times \otimes w_{i j}
$$

In vector form, the series can be written as:

$$
\begin{aligned}
& D_{1}^{*}=\left\{\otimes d_{1,1}^{*}, \otimes d_{1,2}^{*}, \ldots, \otimes d_{1, n}^{*}\right\} \\
& D_{2}^{*}=\left\{\otimes d_{2,1}^{*}, \otimes d_{2,2}^{*}, \ldots, \otimes d_{2, n}^{*}\right\} \\
& D_{m}^{*}=\left\{\otimes d_{m, 1}^{*}, \otimes d_{m, 2}^{*}, \ldots, \otimes d_{m, n}^{*}\right\}
\end{aligned}
$$

Step 5. Determine the weighted grey reference alternative. The reference alternative is the best obtainable alternative based on the performances of the alternatives on every criterion, which is the optimal alternative [88].

$$
D_{0}^{*}=\left\{\otimes d_{01}^{*}, \otimes d_{02}^{*}, \ldots, \otimes d_{0 n}^{*}\right\}
$$

where

$$
\otimes d_{0 j}^{*}=\left[\max _{1 \leq i \leq m} d_{i j}^{*} \max _{1 \leq i \leq m} \frac{d_{i j}^{*}}{d_{j}}\right] .
$$

Step 6. Calculate the differences between the weighted reference alternative and weighted standardized decision matrix. This is measured as the distances between two arbitrary interval numbers as given in Equation (7).

$$
\begin{gathered}
\delta_{i j}=\left|\otimes d_{0 j}^{*}-\otimes d_{i j}^{*}\right| \\
=\max \left(\left|\underline{d}_{0 j}^{*}-\underline{d}_{i j}^{*}\right|,\left|\overline{d_{0 j}^{*}}-\overline{d_{i j}^{*}}\right|\right),
\end{gathered}
$$

and

$$
\Delta=\left(\begin{array}{cccc}
\delta_{1,1} & \delta_{1,2} & \cdots & \delta_{1, n} \\
\delta_{2,1} & \delta_{2,2} & \cdots & \delta_{2, n} \\
\vdots & \vdots & \ddots & \vdots \\
\delta_{m, 1} & \delta_{m, 2} & \cdots & \delta_{m, n}
\end{array}\right)
$$

Step 7. Calculate the grey relational grade. The grey relational grade is calculated from the grey relational coefficient of the weights using the following formula:

$$
r_{i}=\frac{1}{n} \sum_{j=1}^{n} \gamma_{i j}
$$


where the grey relational coefficient is

$$
\gamma_{i j}=\frac{\min _{1 \leq i \leq m 1 \leq j \leq n} \min _{i j} \delta_{i j}+\zeta \max _{1 \leq i \leq m 1 \leq j \leq n} \max _{i j}}{\delta_{i j}+\zeta \max _{1 \leq i \leq m 1 \leq j \leq n} \max _{i j}} .
$$

The grey distinguishing coefficient, $\zeta \in[0,1]$, is the degree to which the minimum score to the maximum score is stressed. The grey distinguishing coefficient is usually $0.5, \zeta=0.5$ [89].

\section{Results and Analysis}

\subsection{Sample Data and Screening}

The evaluation of university reputation as an MCDM problem consists of measuring the performance of each university for every criterion and measuring the preferences of the DMs for the entire criteria. The application of the GRFT weighting method combined with the GRA is reported anonymously since the weights in this research are subjective and neither are we endorsing nor tainting any of these universities. Two sets of questionnaires were designed to evaluate the reputation of four universities: Xi'an AAA University $\left(A_{1}\right), \mathrm{Xi}^{\prime}$ an BBB University $\left(A_{2}\right)$, Xi'an CCC University $\left(A_{3}\right)$, and $\mathrm{Xi}$ 'an DDD University $\left(A_{4}\right)$. The first set of questionnaires were conducted online through a website designed to obtain the performances of each university from the perspective of the students. The second set of questionnaires were in a paper and portable document format (.pdf) designed to obtain the preferences of the DMs for the weights estimation.

The questionnaire developed in the study by Chen and Esangbedo [83] was administered to 300 students from each university, with a total of 1200 students. These students were randomly selected. We began collecting the data from 31 October 2018, and it took an average of 11 days to collect data from these students in these universities. Fifty-one samples of the data collected were removed and classified as unattended responses, and 1149 samples were used for the evaluation, which resulted in a $95.75 \%$ response rate of the questionnaire. Similarly, our choice of DMs was biased and was primarily based on their years of experience. The four DMs had 134 years of cumulative work experience, some as academia and others as top managers in the industry.

\subsection{Application of the GRFT Weighting Method}

In this paper, the GRFT weighting method was applied to estimate the weights of the criteria in grey numbers. The weights are subjective and were based on the preferences of the DMs. The percentage points given to criteria were based on the level of importance. For the second-level criteria, the DMs were asked their ratings twice. One question was asked from a prevention focus orientation, and the other question was asked from a promotion focus orientation. A rating approach is a form of points allocation method, where points are assigned to the criteria based on the level of importance. For uniformity, we requested the DMs to use a percentage in allocating points to all the criteria. Each DM provided the ratings (scores) using a scale of $0-100$ (percentage) for a total of 42 questions, six questions for the first-level criteria and 36 questions for the second-level criteria, as shown in Tables 2 and 3. For clarity, Figure 2 shows a flowchart of this study. Also, we classified the ratings of the DMs to be symmetric RFT ratings if the assigned ratings for prevention and promotion focus questions for the criteria were equal $\left(D M_{i, p}=D M_{i, q}\right)$; otherwise, the ratings were asymmetric RFT ratings. From Figure 3, at least half of the answers given by the DMs were asymmetric. Thus, it may be erroneous to measure the $\mathrm{DMs}^{\prime}$ preferences form a single orientation. 
Table 2. Decision Makers (DMs) ratings for first-level criteria.

\begin{tabular}{ccccc}
\hline First-Level Criteria $\left(c_{\boldsymbol{\alpha}}\right)$ & $\mathbf{D M}_{\mathbf{1}}(\mathbf{\%})$ & $\mathbf{D M}_{\mathbf{2}}(\mathbf{\%})$ & $\mathbf{D M}_{\mathbf{3}} \mathbf{( \% )}$ & $\mathbf{D M}_{\mathbf{4}} \mathbf{( \% )}$ \\
\hline Social Contribution $\left(c_{1}\right)$ & 85 & 90 & 85 & 100 \\
Environments $\left(c_{2}\right)$ & 90 & 90 & 86 & 95 \\
Leadership $\left(c_{3}\right)$ & 85 & 90 & 95 & 100 \\
Funding $\left(c_{4}\right)$ & 70 & 80 & 96 & 100 \\
R\&D $\left(c_{5}\right)$ & 75 & 80 & 96 & 95 \\
Students' Guidance $\left(c_{6}\right)$ & 70 & 80 & 96 & 100 \\
\hline
\end{tabular}

Table 3. DM ratings for second-level criteria.

\begin{tabular}{|c|c|c|c|c|c|c|c|c|c|}
\hline \multirow[t]{2}{*}{ Second-Level Criteria $\left(c_{\alpha-\beta}\right)$} & \multirow[t]{2}{*}{$\begin{array}{c}\text { Second-Level } \\
\text { Criteria INDEX }(v)\end{array}$} & \multicolumn{4}{|c|}{$\begin{array}{l}\text { Prevention Measurements } \\
\qquad(p)(\%)\end{array}$} & \multicolumn{4}{|c|}{$\begin{array}{l}\text { Promotion Measurements } \\
(q)(\%)\end{array}$} \\
\hline & & $\mathrm{DM}_{1}$ & $\mathrm{DM}_{2}$ & $\mathrm{DM}_{3}$ & $\mathrm{DM}_{4}$ & $\mathrm{DM}_{1}$ & $\mathrm{DM}_{2}$ & $\mathrm{DM}_{3}$ & $\mathrm{DM}_{4}$ \\
\hline Citizenship $\left(c_{1-1}\right)$ & 1 & 100 & 90 & 100 & 95 & 100 & 90 & 100 & 98 \\
\hline Employment $\left(c_{1-2}\right)$ & 2 & 100 & 81 & 85 & 100 & 70 & 50 & 85 & 100 \\
\hline Alumni $\left(c_{1-3}\right)$ & 3 & 80 & 90 & 91 & 100 & 100 & 70 & 100 & 100 \\
\hline International Learning $\left(c_{2-1}\right)$ & 4 & 90 & 70 & 100 & 90 & 95 & 70 & 100 & 90 \\
\hline Safety $\left(c_{2-2}\right)$ & 5 & 85 & 90 & 100 & 98 & 85 & 90 & 100 & 98 \\
\hline Campus Location $\left(c_{2-3}\right)$ & 6 & 80 & 60 & 90 & 100 & 85 & 80 & 95 & 90 \\
\hline Course Materials $\left(c_{3-1}\right)$ & 7 & 90 & 90 & 100 & 92 & 70 & 30 & 90 & 85 \\
\hline Lecturers $\left(c_{3-2}\right)$ & 8 & 90 & 70 & 98 & 100 & 90 & 90 & 95 & 100 \\
\hline Administration $\left(c_{3-3}\right)$ & 9 & 85 & 70 & 90 & 100 & 85 & 90 & 90 & 95 \\
\hline Income Level of Parent/Sponsors $\left(c_{4-1}\right)$ & 10 & 50 & 70 & 30 & 80 & 50 & 40 & 30 & 90 \\
\hline Tuition Fees $\left(c_{4-2}\right)$ & 11 & 50 & 20 & 85 & 80 & 70 & 70 & 88 & 80 \\
\hline Scholarships $\left(c_{4-3}\right)$ & 12 & 70 & 90 & 90 & 100 & 85 & 90 & 95 & 100 \\
\hline Industrial Links $\left(c_{5-1}\right)$ & 13 & 75 & 40 & 85 & 90 & 70 & 30 & 81 & 90 \\
\hline Key Projects $\left(c_{5-2}\right)$ & 14 & 90 & 80 & 95 & 98 & 90 & 90 & 92 & 100 \\
\hline Publication $\left(c_{5-3}\right)$ & 15 & 85 & 90 & 95 & 100 & 85 & 80 & 95 & 100 \\
\hline Recommendation $\left(c_{6-1}\right)$ & 16 & 90 & 90 & 100 & 100 & 85 & 50 & 50 & 85 \\
\hline Parents $\left(c_{6-2}\right)$ & 17 & 80 & 30 & 25 & 80 & 85 & 90 & 50 & 78 \\
\hline Students $\left(c_{6-3}\right)$ & 18 & 100 & 90 & 62 & 100 & 85 & 60 & 82 & 96 \\
\hline
\end{tabular}

Based on Equation (8), the grey ratings for the first-level criterion were obtained from Table 2, which is:

$$
\begin{gathered}
C^{\prime}=\otimes c_{1}, \otimes c_{2}, \otimes c_{3}, \otimes c_{4}, \otimes c_{5}, \otimes c_{6} \\
=[85,100],[86,95],[85,100],[70,100],[75,96],[70,100] .
\end{gathered}
$$

Next, the grey ratings for the second-level criteria were obtained using Equations (9) and (10). For example, the first criterion of the second-level criteria, Citizenship $\left(c_{1-1}\right)$, had the grey ratings that are given in Table 4. Similarly, the last criterion of the second-level criteria, Students $\left(c_{6-3}\right)$, is given in Table 4 as well. Other first-level criteria were omitted.

Table 4. Grey ratings for second-level criteria.

\begin{tabular}{cccccc}
\hline$\otimes \boldsymbol{c}_{\boldsymbol{\alpha}-\boldsymbol{\beta}-\boldsymbol{i}}$ & $\mathbf{D M}_{\mathbf{1}}$ & $\mathbf{D M}_{\mathbf{2}}$ & $\mathbf{D M}_{\mathbf{3}}$ & $\mathbf{D M}_{\mathbf{4}}$ & $\otimes \boldsymbol{c}_{\boldsymbol{\alpha}-\boldsymbol{\beta}}$ \\
\hline$\otimes c_{1-1-i}$ & {$[100,100]$} & {$[90,90]$} & {$[100,100]$} & {$[95,98]$} & {$[385,388]$} \\
$\otimes c_{1-2-i}$ & {$[70,100]$} & {$[50,81]$} & {$[85,85]$} & {$[100,100]$} & {$[305,366]$} \\
$\otimes c_{1-3-i}$ & {$[80,100]$} & {$[70,90]$} & {$[91,100]$} & {$[100,100]$} & {$[341,390]$} \\
$\vdots$ & $\vdots$ & $\vdots$ & $\vdots$ & $\vdots$ & $\vdots$ \\
$\otimes c_{6-1-i}$ & {$[85,90]$} & {$[50,90]$} & {$[50,100]$} & {$[85,100]$} & {$[270,380]$} \\
$\otimes c_{6-2-i}$ & {$[80,85]$} & {$[30,90]$} & {$[25,50]$} & {$[78,80]$} & {$[213,305]$} \\
$\otimes c_{6-3-i}$ & {$[85,100]$} & {$[60,90]$} & {$[62,82]$} & {$[96,100]$} & {$[303,372]$} \\
\hline
\end{tabular}




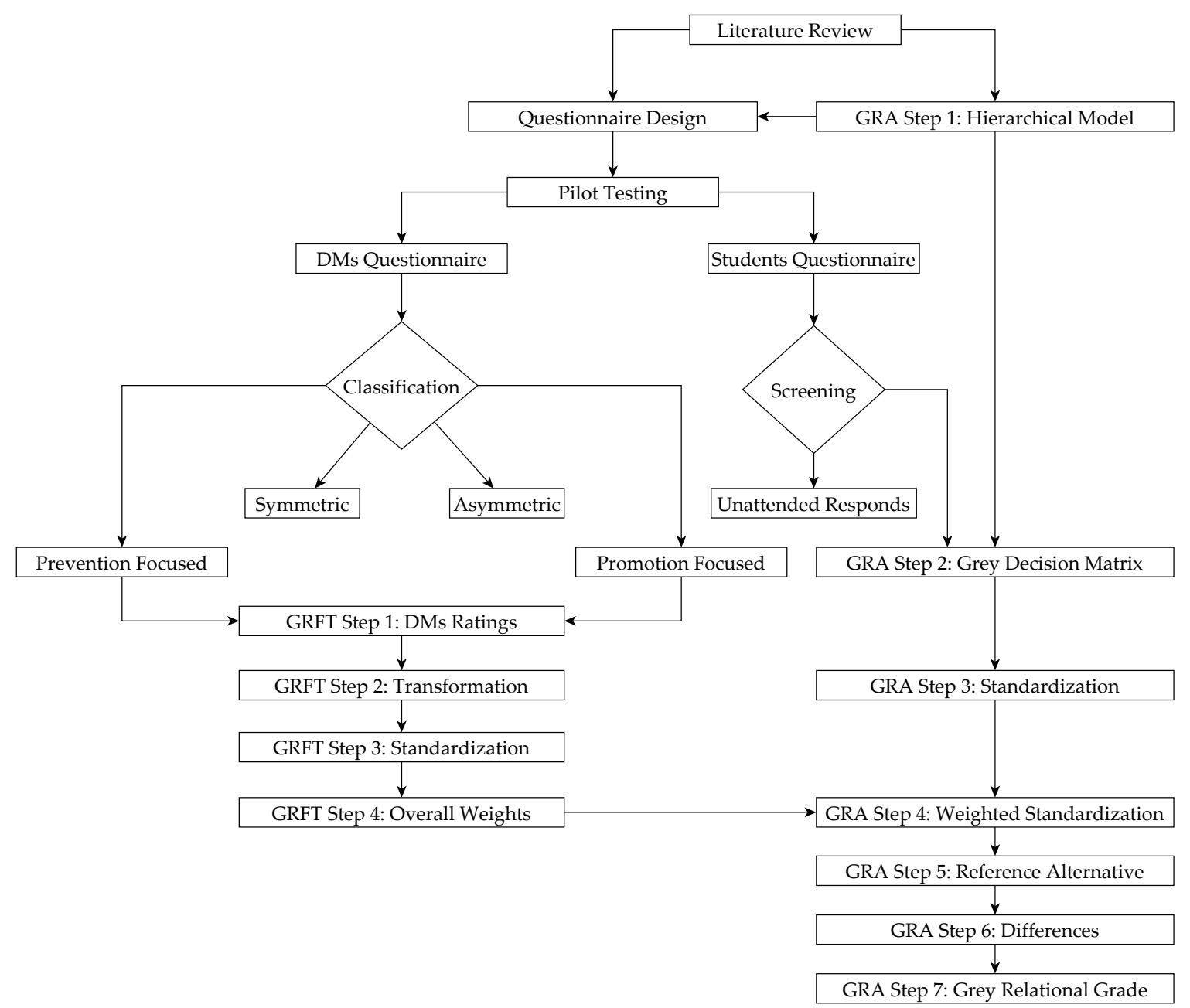

Figure 2. Flowchart of the Grey Regulatory Focus Theory (GRFT) weighting method combined with Grey Relational Analysis (GRA).

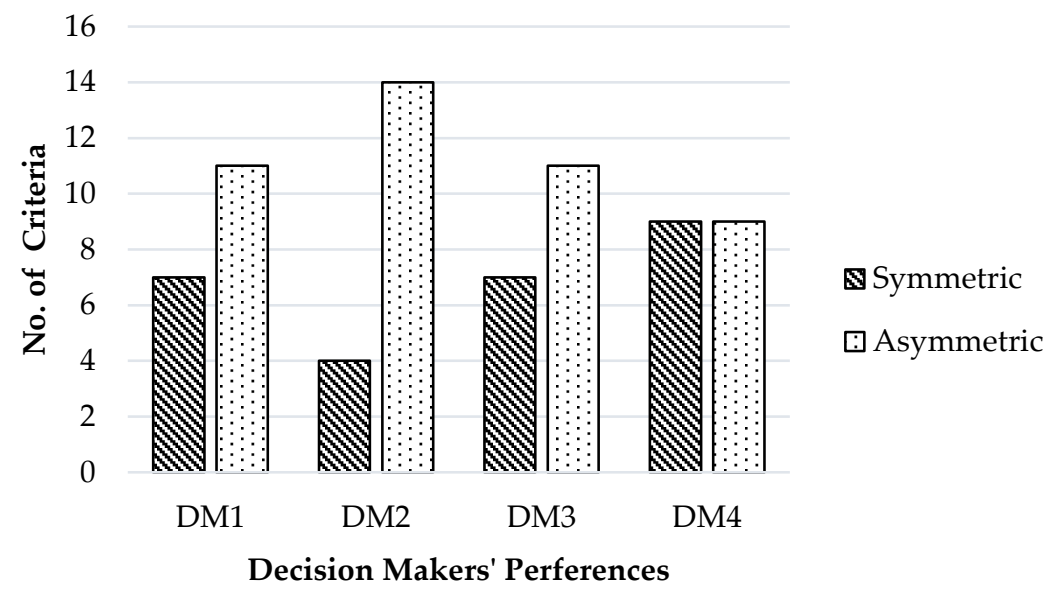

Figure 3. Symmetric to asymmetric ratios of the DMs' preferences.

Then, the first-level criterion weights were standardized using Equation (11), $W^{\prime}=[0.1438$, 0.1692], [0.1455, 0.1607], [0.1438, 0.1692], [0.1184, 0.1692], [0.1269, 0.1624], [0.1184, 0.1692], see Table 5 as well. Also, the second-level criteria were standardized using Equation (12).

$$
W^{\prime}=[0.3365,0.3392],[0.2666,0.3199],[0.2981,0.3409], \ldots,[0.3478,0.3575] .
$$


Table 5. GRFT weights for the evaluation of university reputation.

\begin{tabular}{|c|c|c|c|c|}
\hline $\begin{array}{l}\text { First-Level } \\
\text { Criteria }\left(c_{\alpha}\right)\end{array}$ & $\begin{array}{l}\text { Local Weights } \\
\left(W^{\prime}\right)\end{array}$ & $\begin{array}{l}\text { Second-Level } \\
\text { Criteria }\left(c_{\alpha-\beta}\right)\end{array}$ & $\begin{array}{l}\text { Local Weights } \\
\left(W^{\prime \prime}\right)\end{array}$ & $\begin{array}{c}\text { Effective Weights } \\
\text { in } \%(W)\end{array}$ \\
\hline \multirow{3}{*}{$c_{1}$} & \multirow{3}{*}[0.1438,0.1692]{} & $c_{1-1}$ & {$[0.3365,0.3392]$} & {$[4.84,5.74]$} \\
\hline & & $c_{1-2}$ & {$[0.2666,0.3199]$} & {$[3.83,5.41]$} \\
\hline & & $c_{1-3}$ & {$[0.2981,0.3409]$} & {$[4.29,5.77]$} \\
\hline \multirow{3}{*}{$c_{2}$} & \multirow{3}{*}[0.1455,0.1607]{} & $c_{2-1}$ & {$[0.3217,0.3263]$} & {$[4.68,5.24]$} \\
\hline & & $c_{2-2}$ & {$[0.3428,0.3428]$} & {$[4.99,5.51]$} \\
\hline & & $c_{2-3}$ & {$[0.2941,0.3309]$} & {$[4.28,5.32]$} \\
\hline \multirow{3}{*}{$c_{3}$} & \multirow{3}{*}[0.1438,0.1692]{} & $c_{3-1}$ & {$[0.2466,0.3336]$} & {$[3.55,5.65]$} \\
\hline & & $c_{3-2}$ & {$[0.3184,0.339]$} & {$[4.58,5.74]$} \\
\hline & & $c_{3-3}$ & {$[0.3049,0.3274]$} & {$[4.39,5.54]$} \\
\hline \multirow{3}{*}{$c_{4}$} & \multirow{3}{*}[0.1184,0.1692]{} & $c_{4-1}$ & {$[0.2179,0.2614]$} & {$[2.58,4.42]$} \\
\hline & & $c_{4-2}$ & {$[0.256,0.3355]$} & {$[3.03,5.68]$} \\
\hline & & $c_{4-3}$ & {$[0.3813,0.4031]$} & {$[4.52,6.82]$} \\
\hline \multirow{3}{*}{$c_{5}$} & \multirow{3}{*}[0.1269,0.1624]{} & $c_{5-1}$ & {$[0.2618,0.2802]$} & {$[3.32,4.55]$} \\
\hline & & $c_{5-2}$ & {$[0.3478,0.3623]$} & {$[4.41,5.89]$} \\
\hline & & $c_{5-3}$ & {$[0.3478,0.3575]$} & {$[4.41,5.81]$} \\
\hline \multirow{3}{*}{$c_{6}$} & \multirow{3}{*}[0.1184,0.1692]{} & $c_{6-1}$ & {$[0.2554,0.3595]$} & {$[3.03,6.08]$} \\
\hline & & $c_{6-2}$ & {$[0.2015,0.2886]$} & {$[2.39,4.88]$} \\
\hline & & $c_{6-3}$ & {$[0.2867,0.3519]$} & {$[3.4,5.95]$} \\
\hline
\end{tabular}

Lastly, the effective grey weight for the second-level criteria was calculated using Equation (13), and the results are presented in Table 5.

$$
W=100^{-1} \times([4.84,5.74],[3.83,5.41],[4.29,5.77], \ldots,[3.4,5.95]) .
$$

The weights in percentage are [4.84, 5.74], [3.83, 5.41], [4.29, 5.77], . , , [3.4, 5.95], and the sum of the upper bounds is $100 \%$.

The estimated grey weights of the DMs preferences suggest that the level of funding $\left(c_{4}\right)$ at the disposal of a university is the most important criterion of a reputable university with scholarship $\left(c_{4-3}\right)$ having the highest grey weight of $[4.52,6.82]$. While the least important criterion of a reputable university is the students' guidance $\left(c_{6}\right)$ from the perspective of parents $\left(c_{6-2}\right)$. The level of uncertainty about the weights can be observed as the length of the weight bar shown in Figure 4 . The shortest bar indicates the highest degree of certainty on weight, which corresponds to the safety $\left(c_{2-2}\right)$ condition of the university environments $\left(c_{2}\right)$. By contrast, the longest bar indicates the highest degree of uncertainty, which corresponds to the students' guidance $\left(c_{6}\right)$ in the form of recommendation $\left(c_{6-1}\right)$ student would receive, which can vary widely for various individuals.

\subsection{University Rankings}

The raw data from the survey obtained was transformed into grey numbers by taking the minimum and maximum values of the average value for every criterion in each university. This is because the measurement items for the second-level criterion are reflective constructs, i.e., the measurement items are correlated and the grey number captures the range in which the crisp value can be. The responses were transformed to grey numbers using Equation (26) and the grey decision table is given in Table 6 as well as the grey decision matrix is given in Equation (15).

$$
\otimes d_{i j}=\left[\min _{1 \leq \delta \leq \eta} \bar{C}_{\alpha-\beta-\delta,} \max _{1 \leq \delta \leq \eta} \bar{C}_{\alpha-\beta-\delta}\right]
$$


where $\alpha$ and $\beta$ is the first and second level reference of the criteria $C, \bar{C}$ is the mean of $C$ with the last term $\eta$ for the measured variable $\delta$.

$$
D=\left(\begin{array}{llll}
\otimes d_{1,1} & \otimes d_{1,2} & \cdots & \otimes d_{1,18} \\
\otimes d_{2,1} & \otimes d_{2,2} & \cdots & \otimes d_{2,18} \\
\otimes d_{3,1} & \otimes d_{3,2} & \cdots & \otimes d_{3,18} \\
\otimes d_{4,1} & \otimes d_{4,2} & \cdots & \otimes d_{4,18}
\end{array}\right)=\left(\begin{array}{cccc}
{[4.0548,4.5871]} & {[3.2,4.2677]} & \cdots & {[3.771,4.0806]} \\
{[1.7762,2.1434]} & {[2.0559,2.7028]} & \cdots & {[2.2797,2.6538]} \\
{[1.669,2.1725]} & {[2.0986,2.9437]} & \cdots & {[2.2782,2.7746]} \\
{[1.8451,2.3204]} & {[2.2746,2.9507]} & \cdots & {[2.4542,2.9824]}
\end{array}\right) .
$$

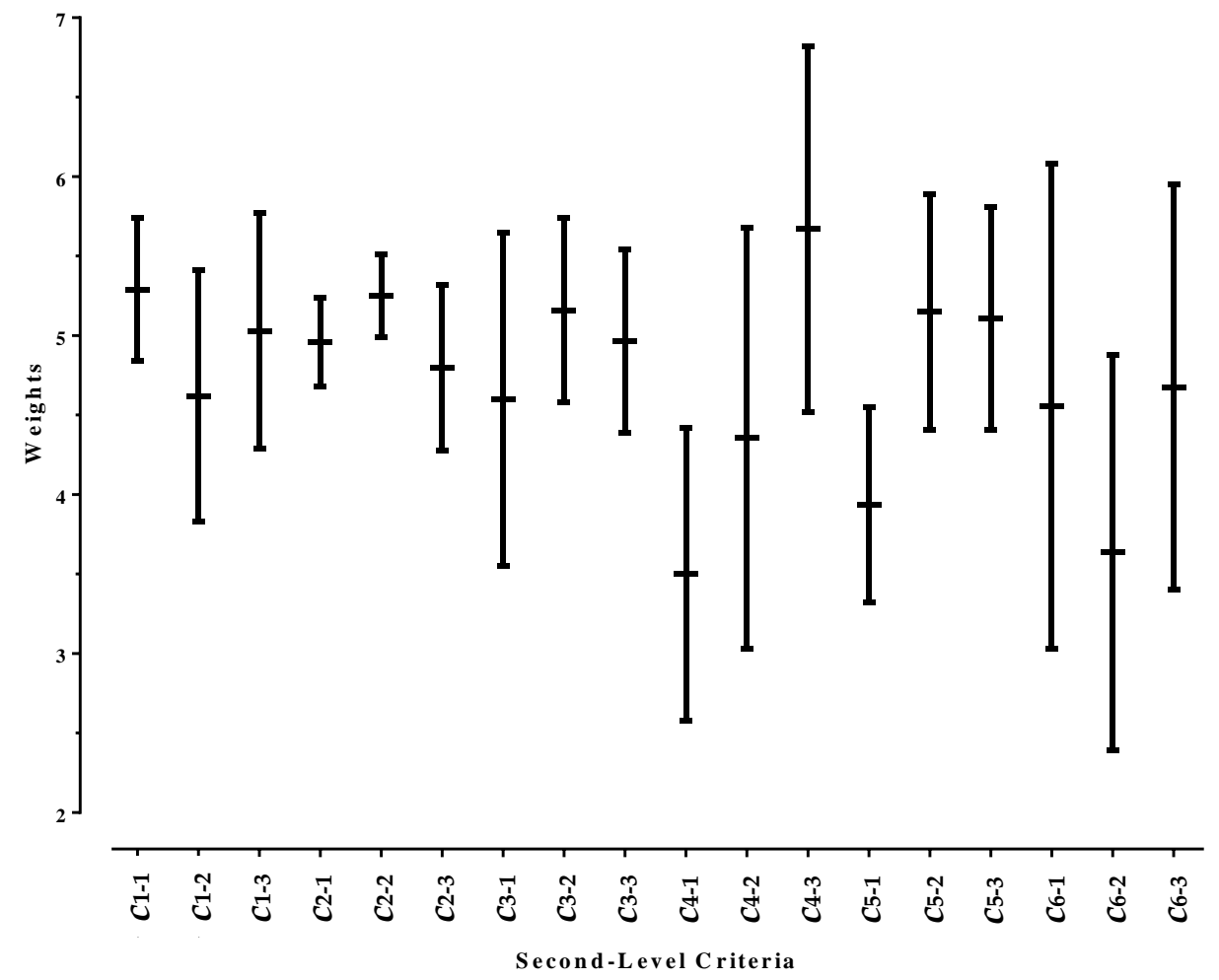

Figure 4. Group DMs of GRFT weights.

Table 6. Grey performances of the universities.

\begin{tabular}{ccccc}
\hline $\begin{array}{c}\text { Criteria Index } \\
v / \text { Universities }\end{array}$ & $A_{\mathbf{1}}$ & $A_{\mathbf{2}}$ & $A_{\mathbf{3}}$ & $A_{\mathbf{4}}$ \\
\hline 1 & {$[4.0548,4.5871]$} & {$[1.7762,2.1434]$} & {$[1.669,2.1725]$} & {$[1.8451,2.3204]$} \\
2 & {$[3.2,4.2677]$} & {$[2.0559,2.7028]$} & {$[2.0986,2.9437]$} & {$[2.2746,2.9507]$} \\
3 & {$[4.2839,4.471]$} & {$[1.8497,2.042]$} & {$[1.8275,2.1127]$} & {$[2.0317,2.3627]$} \\
4 & {$[3.9677,4.7548]$} & {$[1.7762,3.1608]$} & {$[1.9472,3.3521]$} & {$[1.5634,3.5599]$} \\
5 & {$[4.1323,4.4419]$} & {$[1.8077,2.3007]$} & {$[1.9014,2.3415]$} & {$[1.9014,2.1585]$} \\
6 & {$[3.4419,4.2645]$} & {$[2.4056,3.0175]$} & {$[2.3592,2.7852]$} & {$[2.3662,3.1408]$} \\
7 & {$[3.8097,4.0839]$} & {$[2.2238,2.521]$} & {$[2.1408,2.5845]$} & {$[2.3204,2.6092]$} \\
8 & {$[3.9839,4.4161]$} & {$[2.1189,2.3636]$} & {$[2.1338,2.4401]$} & {$[2.2077,2.6092]$} \\
9 & {$[3.5355,4.2065]$} & {$[2.2448,2.6119]$} & {$[2.1338,2.4401]$} & {$[2.243,2.5845]$} \\
10 & {$[3.8161,4.3419]$} & {$[1.9685,2.7657]$} & {$[2.1056,2.7782]$} & {$[1.8697,2.919]$} \\
11 & {$[2.4903,4.2968]$} & {$[1.7343,3.0699]$} & {$[1.8345,3.1831]$} & {$[1.7852,3.2218]$} \\
12 & {$[4.2226,4.529]$} & {$[1.7308,2.2343]$} & {$[1.75,2.1796]$} & {$[1.7324,2.1338]$} \\
13 & {$[3.5774,4.1097]$} & {$[2.1434,2.2762]$} & {$[2.2042,2.4085]$} & {$[2.2958,2.5282]$} \\
14 & {$[4.0419,4.5097]$} & {$[2.0699,2.465]$} & {$[2.1338,2.4859]$} & {$[2.2254,2.507]$} \\
15 & {$[4.1903,4.4452]$} & {$[2.0385,2.2692]$} & {$[2.2535,2.4366]$} & {$[2.331,2.5387]$} \\
16 & {$[3.0484,4.1677]$} & {$[2.3531,3.0559]$} & {$[2.4401,3.2077]$} & {$[2.5739,3.3944]$} \\
17 & {$[2.1645,3.9903]$} & {$[2.3497,3.3741]$} & {$[2.5176,3.6761]$} & {$[2.5739,3.5352]$} \\
18 & {$[3.771,4.0806]$} & {$[2.2797,2.6538]$} & {$[2.2782,2.7746]$} & {$[2.4542,2.9824]$} \\
\hline
\end{tabular}


Thus, the standard grey decision matrix base on Equation (16) is

$$
D^{\prime}=\left(\begin{array}{cccc}
{[0.8528,0.9647]} & {[0.6730,0.8976]} & \cdots & {[0.7931,0.8582]} \\
{[0.3736,0.4508]} & {[0.4324,0.5684]} & \cdots & {[0.4795,0.5581]} \\
{[0.3510,0.4569]} & {[0.4414,0.6191]} & \cdots & {[0.4791,0.5835]} \\
{[0.3880,0.4880]} & {[0.4784,0.6206]} & \cdots & {[0.5162,0.6272]}
\end{array}\right) .
$$

Next, the weighted standardized decision matrix is computed using Equation (19) for which the weights in percentage used are the GRFT weights presented in Equation (25).

$$
D^{*}=\left(\begin{array}{cccc}
{[4.1275,5.5376]} & {[2.5776,4.8558]} & \cdots & {[2.6965,5.1063]} \\
{[1.8080,2.5875]} & {[1.6560,3.0752]} & \cdots & {[3.6301,3.3209]} \\
{[1.6989,2.6226]} & {[1.6904,3.3493]} & \cdots & {[1.6291,3.4720]} \\
{[1.8782,2.8012]} & {[1.8322,3.3573]} & \cdots & {[1.7549,3.7321]}
\end{array}\right)
$$

Based on Equation (20), the weighted grey reference alternative is

$$
D_{0}^{*}=([4.1275,5.5376],[2.5776,4.8558], \ldots,[2.6965,5.1063]) .
$$

The difference between the reference university and the evaluated university are computed using Equation (21)

$$
\Delta=\left(\begin{array}{cccc}
0 & 0 & \cdots & 0 \\
2.9500 & 1.7805 & \cdots & 0.6324 \\
2.9149 & 1.5064 & \cdots & 0.3225 \\
2.7364 & 1.4985 & \cdots & 0.4671
\end{array}\right)
$$

The grey relational grey using Equation (22)

$$
\begin{aligned}
& r_{i}=r_{1}, r_{2}, r_{3}, r_{4} \\
& r_{i}=0.9941,0.4713,0.4857,0.4965
\end{aligned}
$$

i.e., $r_{1}>r_{4}>r_{3}>r_{2}$. This implies that $\mathrm{Xi}$ 'an AAA University is ranked the first position, $\mathrm{Xi}$ 'an DDD University is ranked the second position, $\mathrm{Xi}^{\prime}$ an CCC University is ranked the third position, $\mathrm{Xi}^{\prime}$ an $\mathrm{BBB}$ University is ranked the forth position i.e., $A_{1} \succ A_{4} \succ A_{3} \succ A_{2}$. Xi'an AAA University is ranked the most reputable university from the perspective of students and the subjective weight of the DMs. The most reputable university is consistent with ARWU [90], CWTSLeiden [91], PRSPWUN [92], QS [93], THE [94] and URAP [95].

\section{Conclusions}

Students' perceptions of the reputation of a university and the preferences of the DMs can be explored with the help of psychology. Psychology explores concepts, such as attention, motivation, emotion, brain functioning, intelligence, personality, personal relationships, consciousness, and unconsciousness. A unique theory in psychology is the RFT, which explains how people pursue their goals. Generally, one thing that is definite regarding decision-making in real-life is that "there is uncertainty." The GST provides reasonable slack in the weighting and evaluation variables to account for various degrees of uncertainty. The uncertainty in this research was represented using grey numbers.

Regardless of the evaluation methods used by any ranking index for universities, the weights of the criteria play a key role in the outcome. Therefore, this paper focused on the underlying method for the allocation of various weights to the DM. In other words, this paper provides one major contribution, which is the estimation of the DMs' weight from their RFT orientations in a group decision environment. In addition, this paper developed the GRFT weighting method that can be used in conjunction with 
other MCDM evaluation methods in the literature. Here, the GRFT with the traditional GRA was applied to evaluate the reputation of four universities. The top-ranked university is consistent with other ranking indexes in the literature.

One of the limitations of this research is the inaccuracy that may be introduced by measuring the performances of a university from an abstract measuring instrument. This can be a generic limitation for psychological research in comparison to physical measurement in pure sciences. In addition, the uses of students' perspectives for ranking thousands of universities all over the world may not be appropriate since their perceptions are primarily formed by their local environment. There have been several advances of the classical GRA method. Moreover, for simplicity, the research maintained the use of the traditional GRA and only introduced a new variable, which was the GRFT weighting method. Future research should incorporate the GRFT into sophisticated MCDM evaluation methods, such as TOPSIS and the latest version of ELECTRE [96].

Author Contributions: Conceptualization, Methodology, Writing_-Original Draft, M.O.E.; Supervision, funding acquisition, and validation, S.B.; Writing-Review \& Editing, M.O.E. and S.B.

Funding: This research was funded by Shaanxi Province Soft Science Plan-Key Projects, grant number 2015KRM039.

Conflicts of Interest: The authors declare no conflict of interest.

\section{References}

1. Brown, R.M.; Mazzarol, T.W. The importance of institutional image to student satisfaction and loyalty within higher education. High. Educ. 2009, 58, 81-95. [CrossRef]

2. MOE List of National Colleges and Universities. Available online: http://www.moe.edu.cn/srcsite/A03/ moe_634/201706/t20170614_306900.html (accessed on 2 December 2018).

3. Colman, A.M. What is Psychology? Psychology Press: Hove, UK, 1999; ISBN 978-0-415-16901-1.

4. Henriques, G.R. Psychology defined. J. Clin. Psychol. 2004, 60, 1207-1221. [CrossRef] [PubMed]

5. Higgins, E.T. Beyond pleasure and pain. Am. Psychol. 1997, 52, 1280-1300. [CrossRef] [PubMed]

6. Chelst, K.; Canbolat, Y.B. Value-Added Decision Making for Managers; CRC Press: Boca Raton, FL, USA, 2011; ISBN 978-1-4200-7572-4.

7. Deng, J. The Primary Methods of Grey System Theory, 1st ed.; Huazhong University of Science and Technology Press: Wuhan, China, 1987; ISBN 7-5609-0045-3.

8. Liu, S.; Lin, Y. Introduction to Grey Systems Theory. In Grey Systems Theory and Applications; Understanding Complex Systems; Springer: Berlin/Heidelberg, Germany, 2010; ISBN 978-3-642-16157-5.

9. ARWU World University Rankings 2017 | Academic Ranking of World Universities 2017 | Top 500 universities I Shanghai Ranking - 2017. Available online: http://www.shanghairanking.com/ARWU2017. $\mathrm{html}$ (accessed on 25 January 2018).

10. Studies (CWTS), C. for S. and T. CWTS Leiden Ranking. Available online: http:/ /www.leidenranking.com (accessed on 25 January 2018).

11. Huang, M.-H. Performance Ranking of Scientific Papers for World Universities. Available online: http: //nturanking.lis.ntu.edu.tw/Others/AboutUS-enus.aspx (accessed on 25 January 2018).

12. University Rankings. Available online: https:/ / www.topuniversities.com/university-rankings (accessed on 25 January 2018).

13. World University Rankings 2016-2017 Methodology. Available online: https://www.timeshighereducation. com/world-university-rankings/methodology-world-university-rankings-2016-2017 (accessed on 17 July 2017).

14. Akbulut, U. University Ranking by Academic Performance (URAP) Press Release. Available online: http: / / www.urapcenter.org/2018/ (accessed on 14 February 2019).

15. ARWU Ranking Methodology of Academic Ranking of World Universities. Available online: http:/ / www. shanghairanking.com/ARWU-Methodology-2014.html (accessed on 3 December 2018).

16. Quacquarelli Symonds QS World University Rankings-Methodology I Top Universities. Available online: https:/ / www.topuniversities.com/qs-world-university-rankings/methodology (accessed on 3 December 2018).

17. THE World University Rankings 2018 Methodology. Available online: https:/ /www.timeshighereducation. com/world-university-rankings/methodology-world-university-rankings-2018 (accessed on 3 December 2018). 
18. Saisana, M.; d'Hombres, B.; Saltelli, A. Rickety numbers: Volatility of university rankings and policy implications. Res. Policy 2011, 40, 165-177. [CrossRef]

19. Yu, D.; Wang, W.; Zhang, W.; Zhang, S. A Bibliometric Analysis of Research on Multiple Criteria Decision Making. Curr. Sci. 2018, 114, 747. [CrossRef]

20. MacCrimmon, K.R. Decisionmaking among Multiple-Attribute Alternatives: A Survey and Consolidated Approach; RM-4823-ARPA; The Rand Corporation: Santa Monica, CA, USA, 1968; pp. 1-63.

21. Dinçer, H.; Yüksel, S.; Martínez, L. Balanced scorecard-based analysis about European energy investment policies: A hybrid hesitant fuzzy decision-making approach with Quality Function Deployment. Expert Syst. Appl. 2019, 115, 152-171. [CrossRef]

22. Sullivan, L.P. Quality function deployment. Qual. Prog. 1986, 19, 39-50.

23. Saaty, T.L. Decision making-The Analytic Hierarchy and Network Processes (AHP/ANP). J. Syst. Sci. Syst. Eng. 2004, 13, 1-35. [CrossRef]

24. Hwang, C.L.; Yoon, K. Multiple attribute decision making, methods and applications. In Lecture Notes in Economics and Mathematical Systems; Springer-Verlag: New York, NY, USA, 1981; Volume 186.

25. Petrović, I.; Kankaraš, M. DEMATEL-AHP multi-criteria decision making model for the determination and evaluation of criteria for selecting an air traffic protection aircraft. Decis. Mak. Appl. Manag. Eng. 2018, 1, 93-110. [CrossRef]

26. Hu, J.W.-S.; Hu, Y.-C.; Tsai, A.C.-H. Multiple Criteria Decision Making and General Regression for Determining Influential Factors on S\&P 500 Index Futures. Symmetry 2018, 10, 5.

27. Roy, J.; Pamučar, D.; Adhikary, K.; Kar, K. A rough strength relational DEMATEL model for analysing the key success factors of hospital service quality. Decis. Mak. Appl. Manag. Eng. 2018, 1, 121-142. [CrossRef]

28. Shariat, R.; Roozbahani, A.; Ebrahimian, A. Risk analysis of urban stormwater infrastructure systems using fuzzy spatial multi-criteria decision making. Sci. Total Environ. 2019, 647, 1468-1477. [CrossRef] [PubMed]

29. Ali, S.; Taweekun, J.; Techato, K.; Waewsak, J.; Gyawali, S. GIS based site suitability assessment for wind and solar farms in Songkhla, Thailand. Renew. Energy 2019, 132, 1360-1372. [CrossRef]

30. Arabameri, A.; Rezaei, K.; Cerda, A.; Lombardo, L.; Rodrigo-Comino, J. GIS-based groundwater potential mapping in Shahroud plain, Iran. A comparison among statistical (bivariate and multivariate), data mining and MCDM approaches. Sci. Total Environ. 2019, 658, 160-177. [CrossRef] [PubMed]

31. Sahu, A.K.; Sahu, N.K.; Sahu, A.K.; Rajput, M.S.; Narang, H.K. T-SAW methodology for parametric evaluation of surface integrity aspects in AlMg3 (AA5754) alloy: Comparison with T-TOPSIS methodology. Measurement 2019, 132, 309-323. [CrossRef]

32. Zhang, L.; Xin, H.; Yong, H.; Kan, Z. Renewable energy project performance evaluation using a hybrid multi-criteria decision-making approach: Case study in Fujian, China. J. Clean. Prod. 2019, 206, 1123-1137. [CrossRef]

33. Aghdaie, M.H.; Hashemkhani Zolfani, S.; Zavadskas, E.K. A Hybrid Approach for Market Segmentation and Market Segment Evaluation and Selection: An Integration of Data Mining and Madm. Transform. Bus. Econ. 2013, 12, 431-458.

34. Keršuliene, V.; Zavadskas, E.K.; Turskis, Z. Selection of rational dispute resolution method by applying new step-wise weight assessment ratio analysis (Swara). J. Bus. Econ. Manag. 2010, 11, 243-258. [CrossRef]

35. Kaklauskas, A.; Zavadskas, E.K.; Raslanas, S.; Ginevicius, R.; Komka, A.; Malinauskas, P. Selection of low-e windows in retrofit of public buildings by applying multiple criteria method COPRAS: A Lithuanian case. Energy Build. 2006, 38, 454-462. [CrossRef]

36. Aghdaie, M.H. Data Mining Group Decision-Making with FAHP: An Application in Supplier Evaluation and Segmentation. In Fuzzy Analytic Hierarchy Process; CRC Press: Boca Raton, FL, USA, 2017; ISBN 978-1-4987-3248-2.

37. Wang, H.; Jiang, Z.; Zhang, H.; Wang, Y.; Yang, Y.; Li, Y. An integrated MCDM approach considering demands-matching for reverse logistics. J. Clean. Prod. 2019, 208, 199-210. [CrossRef]

38. Pamučar, D.; Ćirović, G. The selection of transport and handling resources in logistics centers using Multi-Attributive Border Approximation area Comparison (MABAC). Expert Syst. Appl. 2015, 42, 3016-3028. [CrossRef]

39. Kamari, A.; Jensen, S.R.; Corrao, R.; Kirkegaard, P.H. A Holistic Multi-Methodology for Sustainable Renovation. Int. J. Strateg. Prop. Manag. 2019, 23, 50-64. [CrossRef] 
40. Nie, R.-X.; Tian, Z.-P.; Wang, J.-Q.; Hu, J.-H. Pythagorean fuzzy multiple criteria decision analysis based on Shapley fuzzy measures and partitioned normalized weighted Bonferroni mean operator. Int. J. Intell. Syst. 2019, 34, 297-324. [CrossRef]

41. Rezaei, J. Best-worst multi-criteria decision-making method. Omega 2015, 53, 49-57. [CrossRef]

42. Badi, I.; Ballem, M. Supplier selection using the rough BWM-MAIRCA model: A case study in pharmaceutical supplying in Libya. Decis. Mak. Appl. Manag. Eng. 2018, 1, 16-33. [CrossRef]

43. Pamučar, D.; Stević, Ž.; Sremac, S. A New Model for Determining Weight Coefficients of Criteria in MCDM Models: Full Consistency Method (FUCOM). Symmetry 2018, 10, 393. [CrossRef]

44. Pamučar, D.; Lukovac, V.; Božanić, D.; Komazec, N. Multi-criteria FUCOM-MAIRCA model for the evaluation of level crossings: case study in the Republic of Serbia. Oper. Res. Eng. Sci. Theory Appl. 2018, 1, 108-129. [CrossRef]

45. Nunić, Z.B. Evaluation and selection of Manufacturer PVC carpentry using FUCOM-MABAC model. Oper. Res. Eng. Sci. Theory Appl. 2018, 1, 13-28. [CrossRef]

46. Aghdaie, M.H.; Tafreshi, P.F. (Eds.) A new perspective on RFM analysis. In Intelligent Systems: Concepts, Methodologies, Tools, and Applications; IGI Global: Hershey, PA, USA, 2018; ISBN 978-1-5225-5643-5.

47. Stanujkić, D.; Karabašević, D. An extension of the WASPAS method for decision-making problems with intuitionistic fuzzy numbers: a case of website evaluation. Oper. Res. Eng. Sci. Theory Appl. 2018, 1, $29-39$. [CrossRef]

48. Zavadskas, E.K.; Turskis, Z.; Antucheviciene, J.; Zakarevicius, A. Optimization of weighted aggregated sum product assessment. Elektron. Ir Elektrotechnika 2012, 122, 3-6. [CrossRef]

49. Singh, S.; Garg, H. Symmetric Triangular Interval Type-2 Intuitionistic Fuzzy Sets with Their Applications in Multi Criteria Decision Making. Symmetry 2018, 10, 401. [CrossRef]

50. Dursun, M.; Arslan, Ö. An Integrated Decision Framework for Material Selection Procedure: A Case Study in a Detergent Manufacturer. Symmetry 2018, 10, 657. [CrossRef]

51. Ye, D.; Liang, D.; Hu, P. Three-Way Decisions with Interval-Valued Intuitionistic Fuzzy Decision-Theoretic Rough Sets in Group Decision-Making. Symmetry 2018, 10, 281. [CrossRef]

52. Deng, J. Introduction to Grey System Theory. J. Grey Syst. 1989, 1, 1-24.

53. Sifeng, L.; Lin, Y. Grey information: theory and practical applications; Advanced information and knowledge processing; Springer: London, UK, 2006; ISBN 978-1-85233-995-1.

54. Liu, C.-Y.; Tong, L.-I. Developing Automatic Form and Design System Using Integrated Grey Relational Analysis and Affective Engineering. Appl. Sci. 2018, 8, 91. [CrossRef]

55. Yazdani, M.; Kahraman, C.; Zarate, P.; Onar, S.C. A fuzzy multi attribute decision framework with integration of QFD and grey relational analysis. Expert Syst. Appl. 2019, 115, 474-485. [CrossRef]

56. Sefidian, A.M.; Daneshpour, N. Missing value imputation using a novel grey based fuzzy c-means, mutual information based feature selection, and regression model. Expert Syst. Appl. 2019, 115, 68-94. [CrossRef]

57. Ramesh, K.; Baranitharan, P.; Sakthivel, R. Investigation of the stability on boring tool attached with double impact dampers using Taguchi based Grey analysis and cutting tool temperature investigation through FLUKE-Thermal imager. Measurement 2019, 131, 143-155. [CrossRef]

58. Lai, F.; Li, Z.; Zhang, T.; Zhou, A.; Gong, B. Characteristics of microscopic pore structure and its influence on spontaneous imbibition of tight gas reservoir in the Ordos Basin, China. J. Pet. Sci. Eng. 2019, 172, $23-31$. [CrossRef]

59. Zare Mehrjerdi, Y. Strategic system selection with linguistic preferences and grey information using MCDM. Appl. Soft Comput. 2014, 18, 323-337. [CrossRef]

60. Wu, C.-Y.; Chan, H.-T.; Wang, S.-H. Using modified grey relational analysis approach for ERP system providers. In Proceedings of the 2011 6th International Conference on Computer Sciences and Convergence Information Technology (ICCIT), Seogwipo, Korea, 29 November-1 December 2011; pp. 333-337.

61. Kang, H.K.; Kim, D.G.; Jeong, H.W.; Park, G.Y.; Youn, H.-Y. A Novel Interval Grey Number and Entropy-based Solution for Multiple-Criteria Group Decision Making Problem. In Proceedings of the 2012 9th International Conference on Ubiquitous Intelligence Computing and 9th International Conference on Autonomic Trusted Computing (UIC/ATC), Fukuoka, Japan, 4-7 September 2012; pp. 349-356.

62. Zhang, N. Method for aggregating correlated interval grey linguistic variables and its application to decision making. Technol. Econ. Dev. Econ. 2013, 19, 189-202. [CrossRef] 
63. Ma, Z.-J.; Zhang, N.; Dai, Y. Some Induced Correlated Aggregating Operators with Interval Grey Uncertain Linguistic Information and Their Application to Multiple Attribute Group Decision Making. Math. Probl. Eng. 2013, 2013, e160610. [CrossRef]

64. Jin, F.; Liu, P.; Zhang, X. The multi-attribute group decision making method based on the interval grey linguistic variables weighted harmonic aggregation operators. Technol. Econ. Dev. Econ. 2013, 19, 409-430. [CrossRef]

65. Crowe, E.; Higgins, E.T. Regulatory Focus and Strategic Inclinations: Promotion and Prevention in Decision-Making. Organ. Behav. Hum. Decis. Process. 1997, 69, 117-132. [CrossRef]

66. Higgins, E.T. Making a good decision: Value from fit. Am. Psychol. 2000, 55, 1217-1230. [CrossRef]

67. Aaker, J.L.; Lee, A.Y. "I" seek pleasures and "we" avoid pains: The role of self-regulatory goals in information processing and persuasion. J. Consum. Res. 2001, 28, 33-49. [CrossRef]

68. Forster, J.; Higgins, E.T.; Idson, L.C. Approach and avoidance strength during goal attainment: regulatory focus and the "goal looms larger" effect. J. Pers. Soc. Psychol. 1998, 75, 1115-1131. [CrossRef]

69. Shah, J.; Higgins, T.; Friedman, R.S. Performance incentives and means: How regulatory focus influences goal attainment. J. Pers. Soc. Psychol. 1998, 74, 285-293. [CrossRef]

70. Zhao, G.; Pechmann, C. The Impact of Regulatory Focus on Adolescents' Response to Antismoking Advertising Campaigns. J. Mark. Res. 2007, 44, 671-687. [CrossRef]

71. Dijk, D.V.; Kluger, A.N. Task type as a moderator of positive/negative feedback effects on motivation and performance: A regulatory focus perspective. J. Organ. Behav. 2011, 32, 1084-1105. [CrossRef]

72. Bullens, L.; van Harreveld, F.; Förster, J.; Higgins, T.E. How decision reversibility affects motivation. J. Exp. Psychol. Gen. 2014, 143, 835-849. [CrossRef] [PubMed]

73. Kuhn, K.M. Selecting the Good vs. Rejecting the Bad: Regulatory Focus Effects on Staffing Decision Making. Hum. Resour. Manage. 2015, 54, 131-150. [CrossRef]

74. Ahmadi, S.; Khanagha, S.; Berchicci, L.; Jansen, J.J.P. Are Managers Motivated to Explore in the Face of a New Technological Change? The Role of Regulatory Focus, Fit, and Complexity of Decision-Making. J. Manag. Stud. 2017, 54, 209-237. [CrossRef]

75. Lai, C.-Y.; Hsu, J.S.-C.; Li, Y. Leadership, regulatory focus and information systems development project team performance. Int. J. Proj. Manag. 2018, 36, 566-582. [CrossRef]

76. Liao, Z.; Long, S. CEOs' regulatory focus, slack resources and firms' environmental innovation. Corp. Soc. Responsib. Environ. Manag. 2018, 25, 981-990. [CrossRef]

77. Song, J.; Kim, J.; Triche, J.; Kim, M.; Chai, S. The Effects of Institution-Based Trust on Community Commitments: A Regulatory Focus Perspective. SIGMIS Database 2018, 49, 34-53. [CrossRef]

78. Higgins, E.T.; Cornwell, J.F.M. Securing foundations and advancing frontiers: Prevention and promotion effects on judgment \& decision making. Organ. Behav. Hum. Decis. Process. 2016, 136, $56-67$.

79. Lo Gerfo, E.; Pisoni, A.; Ottone, S.; Ponzano, F.; Zarri, L.; Vergallito, A.; Varoli, E.; Fedeli, D.; Lauro, L.J.R. Goal Achievement Failure Drives Corticospinal Modulation in Promotion and Prevention Contexts. Front. Behav. Neurosci. 2018, 12, 71. [CrossRef]

80. Plewa, C.; Ho, J.; Conduit, J.; Karpen, I.O. Reputation in higher education: A fuzzy set analysis of resource configurations. J. Bus. Res. 2016, 69, 3087-3095. [CrossRef]

81. Verčič, A.T.; Verčič, D.; Žnidar, K. Exploring academic reputation - is it a multidimensional construct? Corp. Commun. Int. J. 2016, 21, 160-176. [CrossRef]

82. Vidaver-Cohen, D. Reputation Beyond the Rankings: A Conceptual Framework for Business School Research. Corp. Reput. Rev. 2007, 10, 278-304. [CrossRef]

83. Chen, C.; Esangbedo, M.O. Evaluating University Reputation Based on Integral Linear Programming with Grey Possibility. Math. Probl. Eng. 2018, 2018. [CrossRef]

84. Liu, S.F.; Forrest, J. The current developing status on grey system theory. J. Grey Syst. 2007, 19, 111-123.

85. Li, Q.; Zhao, N. Stochastic interval-grey number VIKOR method based on prospect theory. Grey Syst. Theory Appl. 2015, 5, 105-116. [CrossRef]

86. Dawood, H. Theories of Interval Arithmetic: Mathematical Foundations and Applications; LAP LAMBERT Academic Publishing: Saarbrücken, Germany, 2011; ISBN 978-3-8465-0154-2.

87. Zhang, J.; Wu, D.; Olson, D.L. The method of grey related analysis to multiple attribute decision making problems with interval numbers. Math. Comput. Model. 2005, 42, 991-998. [CrossRef] 
88. Li, G.-D.; Yamaguchi, D.; Nagai, M. A grey-based decision-making approach to the supplier selection problem. Math. Comput. Model. 2007, 46, 573-581. [CrossRef]

89. Deng, J. The Primary Methods of Grey System Theory; Huazhong University of Science and Technology Press: Wuhan, China, 2005; ISBN 7-5609-3436-6.

90. ARWU World University Rankings 2018 | Academic Ranking of World Universities 2018 | Top 500 universities I Shanghai Ranking - 2018. Available online: http:/ /www.shanghairanking.com/ARWU2018. html (accessed on 20 December 2018).

91. Centre for Science and Technology Studies (CWTS) CWTS Leiden Ranking. Available online: http:/ / www. leidenranking.com (accessed on 20 December 2018).

92. Performance Ranking of Scientific Papers for World Universities China World University Rankings By 2018. Available online: http:/ / nturanking.lis.ntu.edu.tw / ByCountry/2018/CN (accessed on 20 December 2018).

93. QS University Rankings: Asia 2019. Available online: https://www.topuniversities.com/universityrankings/asian-university-rankings/2019 (accessed on 20 December 2018).

94. Times Higher Education World University Rankings 2019. Available online: https:/ / www.timeshighereducation. com/world-university-rankings/2019/world-ranking (accessed on 20 December 2018).

95. University Ranking by Academic Performance URAP 2018-2019 Ranking by Country. Available online: http:/ / www.urapcenter.org/2018/ country.php?ccode=CN\&rank=all (accessed on 20 December 2018).

96. Roy, B. Classement et choix en présence de points de vue multiples (The ELECTRE method). RAIRO Oper. Res. Rech. Opérationnelle 1968, 2, 57-75.

(C) 2019 by the authors. Licensee MDPI, Basel, Switzerland. This article is an open access article distributed under the terms and conditions of the Creative Commons Attribution (CC BY) license (http:/ / creativecommons.org/licenses/by/4.0/). 